\title{
CONTRIBUTION OF VISUAL REPRESENTATION OF ISLAMIC CELEBRATIONS
}

\author{
ARWA A. ALGHAMDI \\ Independent Researcher, Jeddah, Saudi Arabia
}

\begin{abstract}
Visuals influence community practices in celebrating holidays that lead to global recognition. The modern Islamic celebrations such as Ramadan, Hajj, and Eid have been influenced by many factors such as the Islamic doctrine, Islamic architecture, art, and local cultures. As a result, Islamic holidays are not necessarily tied to a specific theme or iconography and are subject to different regional interpretations, which has led to a lack of international uniformity. This research aims to identify the significance of visual representation in Islamic holidays. A descriptive and quantitative analytical approach was used as a method of investigation. An artistic/embodied practice was used by observing and engaging in a "Make a Lantern" event that gathers family members to create Ramadan decorations in addition to a survey that received over 50 individual responses that investigate the visual traditions and their impact. The results show that there are three main areas that emphasize on the importance of visuals for Islamic celebrations: building one's identity, fighting Islamophobia, and creating opportunities for artists and designers. The researcher recommends that governmental and private entities should invest-in and encourage their local citizens to highlight their culture through artistic visual creations that connect Muslims' religious practices to their culture and excite innovation and creativity to benefit the local economy and enhance Islamic tourism. This research may benefit the arts and crafts industry and create opportunities for designers and artists.
\end{abstract}

Keywords: Islamic celebrations, holiday visuals, Islamic art, religious branding, heritage preservation.

\section{INTRODUCTION}

Celebrations are considered as an essential aspect of an individual's life. Holidays make a significant part of what people usually celebrate. In holiday celebrations, visuals appear to represent the occasions in ways that are reflective of the cultural understanding of these events. Visuals have gained a fundamental position in recent days for perspicuous and impactful delivery of thoughts and beliefs. This research studies the impact of visuals of the four main Islamic holidays; Ramadan, Eid Al-Fitr, Hajj, Eid Al-Adha in Saudi Arabia.

The current Islamic celebrations, in general, do not reflect the richness of the Islamic Art or its culture on a visual level, as it is unusual for Muslims to have inner beliefs and practices separated from showing on external appearances and practices. Visuals of Islamic holidays should reflect the magnificence, holiness, and joyfulness of these special occasions.

This research tries to answer the questions of what value does visual representation add for Islamic communities to have an identifiable image of how the holiday celebrations expected to look like? Multiple primary and secondary resources were used for data collection. The research highlights that the inclusion of visuals in Islamic celebrations has valuable impacts on individuals and communities. Building one's identity, fighting Islamophobia, and creating opportunities for artists and designers are some of the advantages that come with visual representation. 


\section{LITERATURE REVIEW}

\subsection{Significance of holiday celebrations}

The celebration of holidays has been defined as social [1, p. 43] and formal events. In most cases, holiday celebrations share some features such as: "repetition and order, dramatic presentation of cultural symbols, entertainment, a collective group orientation, and active participation" [2, p. 67]. Prior studies have identified the importance of celebrating holidays on different aspects of human life. In this research, the focus will be on the psychological and spiritual impacts of celebrating holidays.

Generally speaking, the psychological impact of practicing celebrations is known to enhance an individual's well-being, increase optimism, and help overcome stress caused by daily challenges. Emotional and sociological needs are also proven to leave a considerable impact on human's life. From an emotional perspective, the engagement in celebrations encourages feelings, expressions, values, beliefs, and morals in different ways to create and share merriment and joy. In many cases, enjoyment motives become the reason why people celebrate instead of remembering the primary purpose or religious reasons behind the celebrations. The sociological impact of holiday celebrations shows in the development of an essential perception of one's culture [2, p. 66-73], [3, p. 538], and serve the building of a person's identity, and reinforce meanings of sense of belonging to a larger entity [1, p. 43].

Spirituality is a complicated concept for individuals that includes "values, attitudes, perspectives, beliefs, and emotions that constitute the inner core of a person" [2, p. 71] that appear when somebody is engaged with celebrations. Knowing that not all celebrations are considered religious, spirituality is a concept that is commonly associated with religious practices and increased by them. Celebrating religious holidays is a performance of beliefs that act like an evident declaration and build up the believer's relation to God [2, p. 68]. In different religions like Christianity, Judaism, and Islam, the celebration is considered one of the rites that are commanded or recommended for adherents to practice. "The term spirituality in Islamic languages is connected to either the word ruh denoting 'Spirit' or ma'na signifying 'meaning"" [4], and both meanings aspire to strengthen the connection with God and inner beliefs. Islam has encouraged training oneself to practice good deeds and recognizes the consideration of preparing oneself for the holidays as one. These teachings of Islam come to help Muslims take advantage of that holy time and work on developing their relationship with God and increase spirituality to achieve piety, that is a noble goal for the majority of Muslims, as the verse from Qur'an states that "those who honor God's rites show the piety of their hearts" (22:32). That verse emphasizes that the more Muslims are respecting, embracing, and showing God's rites (in this case celebrating the Islamic holidays) the closer they become to devoutness. On the other hand, the lack of proper spiritual and practical practices might be a negative indicator of the decreasing level of a Muslim's piety for individuals and communities.

\subsection{Islamic teachings on celebrations}

Islamic celebrations have gained recognition for the high values of reward. Holidays and other occasions are considered blessed times because they are when God multiply the reward for good deeds by tenfold or more "and Allah multiplies 'the reward even more' to whomever He wills. For Allah is All-Bountiful, All-Knowing” Qur'an (2:261). Islamic teachings consider celebrating as a form of worship. Although there are only two Islamic Holidays 
according to Hadith, Eid Al-Fitr and Eid Al-Adha, there are other sacred days in the Islamic calendar that are worth noting such as Ramadan and Hajj [5, p. 21].

Ramadan is the ninth month of the Islamic calendar and considered the most valuable month of the Islamic year for the occurrence of when the Qur'an was revealed to Prophet Mohammed (PBUH), and the holding of Laylat Al-Qadr (The Night of Decree). It is the month when Muslims worship God by fasting from dawn until sunset along with different voluntary practices such as Taraweeh and Tahajjud (long night prayer), charity and bonding with family and relatives aiming for God's mercy and redeeming from the Hellfire.

Eid Al-Fitr (Holiday of breaking the fast) is the celebration that marks the end of Ramadan, and it comes to praise Muslim nations on the accomplishment of fasting a whole month and reward them for the good deeds that they have been doing during the month of Ramadan. Muslim observe Eid by giving mandatory Zakah donation that is around $\$ 7$ per family member for helping the poor. They are also encouraged to buy new clothes and attend Eid prayer where it is usually held at an open space or the largest mosque in the area to connect with other people and exchange greetings, sweets and Eidiyya (a small amount of money given to children).

Hajj is the name for the Islamic pilgrimage to Mecca in the last month of the Islamic calendar, Dhu al-Hijjah. Muslims are required to do it once in a lifetime if possible. When Hajj has been performed as God commanded, Muslims to be rewarded by absolute forgiveness for all previous sins in the afterlife. Nonparticipants of pilgrimage can fast voluntarily, recite Qur'an and practice other good deeds to take advantage of the holy time.

Eid Al-Adha (Holiday of Sacrifice) is the holiday that marks the 10th day of Dhu al-Hijjah. Muslims are encouraged to sacrifice cattle on this holiday following the Abrahamic example when God sent him a lamb, replacing the sacrifice of his son Ishmael. Islam recommends dividing the meat of the sacrifice into three sections: for immediate family, friends, and the poor. This division encourages people to connect with their community and help one another. Eid prayer is also held as in Eid Al-Fitr with similar traditions.

\subsection{Visuals and holidays}

\subsubsection{Significance of visual representation}

Visual imagery plays a vital role in the daily experiences in "memory, daydreaming, and creativity" [6], and because of that, visual representation has gained its significance in the consolidation of an entity, philosophy or organization, and has been used for country flags, and political and intellectual movements. Icons or logos alongside of colors have high impacts on expanding recognition, delivering meanings and values, and evoking emotions [7].

Einstein [8] considers religions as commodities that promote benefits for their followers; therefore, faith branding is a necessity. Temporal [9] emphasizes that Islamic countries should pay closer attention to branding on national and local levels to cope with the fast-paced change in modern days, build financial and strategic strengths, and lead the impressions of Islamic countries.

\subsubsection{History of other holidays' visual representation}

To gain a better understanding of the visual branding of holidays, it is important to study other religious celebrations and how they developed their visual iconography and traditions. Christmas is one of the main holidays that are internationally known for its rich and remarkable imagery and considered as the "world's most celebrated holiday" [10]. According to Whiteley [11], many Christmas activities and visuals were inspired by texts and 
illustrations for magazines about Christmas. For instance, the modern Santa Clause was created by Clement Clark Moore of collective narrations in his poem "A Visit From St. Nicholas." In the book Stories behind the great traditions of Christmas, Collins [10] explains the origins of Christmas visuals, that the tradition of bringing an evergreen tree inside the house had started more than a thousand years ago when Scandinavian Vikings looked up to it as a symbol of strength and hope during hard and depressing winter days. Collins [10] continues to explain the origin of one of the most recognizable visual elements in the Christmas imagery, the green, red and gold color combination. Even though no one knows how these three colors became the colors of Christmas, but the ancient cultures valued the color green for representing life from the survival of evergreen trees in the harsh winters, the color red comes to contrast that meaning to symbolize the blood of Jesus on the cross, while the color gold represents "wealth and royalty" and the shine of stars. That results in what Whiteley [11] has described, that "a traditional Christmas" is a phrase that comes with an identifiable image of how the celebration expected to look like.

\subsubsection{Islamic art influence on holiday visuals}

The influence of Islam on human development has resulted in what is called Islamic art, which reflects the soul of a Muslim believer [4]. Islamic Art is a term that covers the different visual arts such as architecture, calligraphy, painting, ceramics, and textiles since the seventh century featuring different themes such as arabesque and patterns of the repetition of floral and geometrical shapes. Despite that Islam has no official religious symbols, some common visuals appear in some cultural celebrations such as the crescent, stars, lanterns, and sheep illustrations that were inspired by Qur'an and Hadith, or local events. Furthermore, Islamic texts have influenced people's preferences when it comes to colors. For instance, Green in Islam has a special place for repetitive use to describe paradise in Qur'an. "Reclining on green Cushions and rich Carpets of beauty" (55:76), and "Upon them will be green garments of fine silk and heavy brocade, and they will be adorned with bracelets of silver, and their Lord will give to them to drink of a Water Pure and Holy" (76:21). These descriptions and promises of Qur'an evoke imagination which might be the reason that led artists to recreate Islamic arts and visuals featuring the color green.

In holiday greeting cards, some common colors are used such as dark blue and gradients of magenta and violet for no obvious reasons. Recreating the sky shades at sunrise or sunsets could be a valid explanation of this trend since all Islamic holidays happen during or at the rising or setting of the sun, and the high value of Ramadan' night-time.

The tie of Islamic art and Islamic spirituality is close and inevitable. "The Muslim aesthetician and creative artist equate his every moment spent in the creation of an Islamic art form as prayer ('ibadat) in which man's soul communicates God and acknowledges His Presence everywhere" [4]. That explains the strong connection Muslims around the world have regardless of their cultural background toward this kind of art and prefer to use it in their visual representation to increase the impact of spirituality.

\subsubsection{Cultural influence on holiday visuals}

Muslim-majority countries are 45 countries located in the Asia Pacific, Middle East, North and Sub-Saharan Africa, Europe, North, and Latin America [12]. Environment and culture are two factors that inspire and affect the creation of artistic visuals for holidays. After looking at the reasoning behind some of the featured visuals at Christmas, it is clear that those visuals were inspired by the local environment and culture such as the Pine trees and Moore's writing and reflecting the rich and unique local cultures. 
Egypt and Morocco are two Muslim-majority and African countries that led and impacted the development of the visual representation of the Islamic celebrations. The culture and environment are reflected in the creation and application of the artistic elements such as materials, motifs, and colors which led to a bolder adaptation and application. A unique element that signifies the Egyptian visuals is the Khayamiya textile that was used historically in lining the interior of tents and applied on lanterns and other celebratory elements. Another example is the Moroccan brass lanterns that are embellished with different designs that are influenced by the local or Islamic art and then pierced with hundreds of drills so the light reflects the beautiful shades on surfaces.

\section{METHODOLOGY}

For the rarity of resources on the research topic, multiple methodological approaches were taken in order to investigate the value of visual representation in holidays. Alongside the secondary and tertiary resources, three methods were conducted in this research.

First, an Artistic/Embodied Practice was undertaken. Skains [13] argues that practice-based methodologies inspect engagement in the creation from a closer perspective of art analysis (2018). "Make a Lantern" is an art class that offers family members to gather and embellish their lanterns that are used for Ramadan decorations. The event was held at Bellevue community center in Bellvue, WA on April 28, 2019, and attended by people from different backgrounds. The purpose of this engagement was to observe and engage in the different impacts of celebratory practices.

Second, in order to understand the celebrations of Islamic holidays in the Muslim community, a small survey was conducted on May 21, 2019, to investigate the visual practices and the possible impact of using them. Participants varied from different countries in the Middle East, Africa and Northern America. The survey has received over 50 individual responses on 15 questions containing both close-ended and open-ended questions on the following topics:

- Special traditions, rituals on Islamic holidays.

- Active participation and motives behind engaging/hosting Islamic celebrations.

- Impact of engagement on spirituality, connection with oneself and community.

- Feelings experienced when surrounded by visual festivities.

- Making or supplying visual decorations options.

- The readiness of local markets with supplies and themes and their impact on the rate of celebration.

Third, an interview was done on May 9, 2019, with two leading business owners in the Arab community focusing on the visual development of Eid celebrations, Rafah Sahab and Rola Badkook, the founders of Rock. Paper. Scissor studio that aims to enhance communication in communities through game designs with culturally inspired content, and investigating the state of the market.

\section{RESULTS AND DISCUSSION}

Even though each holiday came with its specific teachings and recommended worships such as special prayers and rites, in different sayings from the Hadiths, Islam encouraged Muslims to embrace the happiness and joyfulness during holidays with specific determinations, except for practicing Islamic taboos.

This broad Islamic direction on embracing festive emotions can be interpreted in many different ways. One way to understand it can be not to narrow down the options for Muslims or over-burden them with whatever is beyond their capabilities. Another reasoning is that 
Islam is a diverse religion, and its adherents come from various cultures that have different interpretations and meanings of joy and happiness.

After reviewing the survey results and attending a Make a Lantern event, it became clear that Muslims are eager to develop and enhance the way they celebrate Islamic holidays. The survey, interviews and artistic practice were intended to answer the research question: What is the possible significance of visual representation to Islamic holidays? As per the findings, the inclusion of visuals in Islamic celebrations has valuable impacts on individuals and communities such as building one's identity, fighting Islamophobia, and create opportunities for artists and designers.

\subsection{Building one's identity}

Visuals help the establishment and confirmation of a Muslim's identity. Existing Islamic visuals like Hijab reinforce inner beliefs on an outer level and help Muslims being distinguished for others to respect what they believe in and stand for with minimal explanation. For children, engaging with visuals will also make "an important learning process" [14] to learn who they are. Muslims who live in non-Muslim-majority counties who witness other faith celebrations struggle with explaining to their children why they should not be celebrating them too. Despite the fun and beautiful decorations, the celebration of Christmas, for example, is against Islamic beliefs. Celebrating Christmas for Muslims indicates the affirmation of the divinity of Christ, while a fundamental Islamic belief to teach children that Christ was sent to his nation as a messenger. What creating visuals for Islamic holidays does is educate children of their religion and traditions, strengthen family bonds, and connect them to different Islamic communities.

Visuals can work as an invitation to bring different people together and building communities. They tend to have the ability to send positive impacts while remaining inclusive by matching the human nature of visual thinking and rise above the barrier of language [7]. Sahab [15] mentioned that localizing the celebrations contribute to the building of the community and create better engagement.

In the survey, when participants were asked to describe the impacts of visually prepared and decorated places for Islamic holidays, $92 \%$ of respondents expressed feelings of joy and happiness, $47 \%$ of respondents feel connected to their community, $68 \%$ of respondents develop feelings of belonging. That reinforces the value of visual representation. It was also noticed in the Make a Lantern event (Fig. 1) that the community needs Islamic themed gatherings, that more than one hundred participants came to the event in 2019 compared to thirty in 2018. In conversations, many people expressed that Muslim communities of Bellvue and Seattle are isolated based on language and nationality, and the event helped to introduce them to each other and to make new friends and connections.
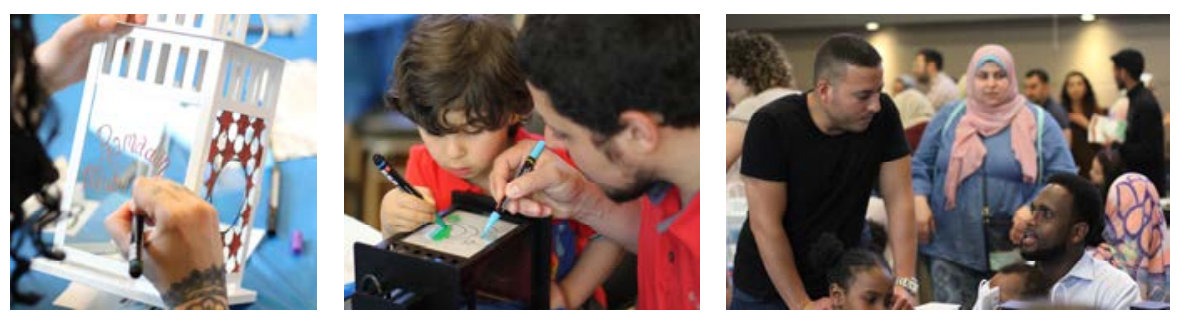

Figure 1: Different types of engagements during a Make a Lantern event. (Source: Author.) 


\subsection{Fighting Islamophobia}

With the significant efforts that are done around the world to reinforce Islamophobia, the embrace of Islamic holiday celebrations will serve as a noiseless counterattack in response to the false accusations of Islam and Muslims. Visual representation of the holidays is a great way to introduce the real Islamic values and beliefs and lead the image and impressions left in people's hearts and minds. In personal communication, Badkook [16] notes that visuals play a vital role in filtering the negative side of the cultural stereotypes by not highlighting them, such as racism, racial biases, and underestimation of women's practices. It is often heard that Muslims who live in a non-Muslim majority country do not feel safe all the time to express their faith publicly. The survey results have shown that Muslims actually feel pride by $33.3 \%$, belonging by $35 \%$ and solidarity with other Muslim communities by $47 \%$.

\subsection{Create opportunities for artists and designers}

The growth of the visual holiday industry has economic values that will contribute to the enhancement of the Muslim communities. Survey results showed that $31.4 \%$ of respondents said that they are not satisfied with the visual materials that are in the market, and $70 \%$ of respondents prefer to make their own decorative visuals instead. The creation of holiday visuals will create work opportunities for designers, artists, and anyone in the creative and entertainment industry and encourage competition. The survey shows that more than $43.1 \%$ of respondents think the readiness of themes and celebration supplies encourage the celebration. In order to create a visual identity of a nation, it is important that it becomes inspired by its specific environment and cultural background. That offers an open horizon for artists to excel and create in a high-demand market and fulfill the communities' needs. Furthermore, as mentioned earlier, the creation of Islamic art is considered some form of Prayer. Whether an individual is creating the festive artistic visuals, or just observing it, the exposure to Islamic visuals during holidays result is the increase of spirituality. The survey results confirm this argument, $68.6 \%$ of respondents said that their motive for participating and making festive visuals is the reward from God.

\section{CONCLUSIONS}

The need for visual representation in Islamic celebrations is rapidly increasing with the increase of multiple media platforms. Islamic cultures should take place in this growth and force their existence. The possible impact of Islamic visual representation on individuals and communities such as building one's identity, fighting Islamophobia, and create opportunities for artists and designers are crucial but not limited by it.

The researcher recommends that government entities should support the transformation of the Islamic visuals, and empower designers to create their own representation that is informed by their culture. That would allow communities to understand that true Islam comes supportive of cultures not opposed to it. She also recommends that business owners and investors should lead a healthy competitive environment that offers a variety of Islamic visual elements for consumers, and invest in local artists and designers. In addition, she recognizes the ripple effect that small initiatives that artists and designers can create in their creative community and hopefully the industry. 


\section{REFERENCES}

[1] Woodward, M., Rohmaniyah, I., Amin, A. \& Coleman, D., Muslim education, celebrating Islam and having fun as counter-radicalization strategies in Indonesia. Perspectives on Terrorism, 4, pp. 28-50, 2010.

[2] Luboshitzky, D., \& Bennett Gaber, L., Holidays and celebrations as a spiritual occupation. Australian Occupational Therapy Journal, 48(2), pp. 66-74, 2001.

[3] Khan, Z.H., \& Watson, P.J., Religious orientation and the experience of Eid-ul-Azha among Pakistani Muslims. Journal for the Scientific Study of Religion, 43(4), pp. 537545, 2004. DOI: 10.1111/j.1468-5906.2004.00254.x.

[4] Saeed, K.M., Islamic art and its spiritual message. International Journal of Humanities and Social Science, 1(2), pp. 227-234, 2011.

[5] Porterfield, J., Islamic Customs and Culture, Rosen Pub: New York, 2009.

[6] Zeman, A.Z., Dewar, M. \& Della Sala, S., Lives without imagery-congenital aphantasia. Cortex, 73, pp. 378-380, 2015.

[7] Alihodzic, V., Brand Identity Factors Developing A Successful Islamic Brand, Anchor Academic Pub: Hamburg, 2013.

[8] Einstein, M., Brands of Faith: Marketing Religion In A Commercial Age, Routledge: London, 2008.

[9] Temporal, P., Islamic Branding and Marketing: Creating A Global Islamic Business, John Wiley: Singapore, 2011.

[10] Collins, A., Stories Behind the Great Traditions of Christmas, Zondervan: Grand Rapids, 2003.

[11] Whiteley, S., Christmas, Ideology and Popular Culture, Edinburgh University Press: Edinburgh, 2008.

[12] World Population Review, Muslim majority countries 2020. http://worldpopulationreview.com/countries/muslim-majority-countries/.

[13] Skains, R.L., Creative practice as research: Discourse on methodology. Media Practice and Education, 19(1), pp. 82-97, 2018. DOI: 10.1080/14682753.2017.1362175.

[14] Mazumdar, S. \& Mazumdar, S., The articulation of religion in domestic space: Rituals in the immigrant Muslim home. Journal of Ritual Studies, 18(2), pp. 74-85, 2004.

[15] Sahab, R., Personal interview May 9, 2019.

[16] Badkook, R., Personal interview May 9, 2019. 